Portland State University

PDXScholar

6-16-2021

\title{
Should Synergy Alone be Accepted as Justification for Premia Paid in M\&A?
}

Sebastian Araguas

Portland State University

Follow this and additional works at: https://pdxscholar.library.pdx.edu/honorstheses

Part of the Finance and Financial Management Commons Let us know how access to this document benefits you.

\section{Recommended Citation}

Araguas, Sebastian, "Should Synergy Alone be Accepted as Justification for Premia Paid in M\&A?" (2021). University Honors Theses. Paper 1081.

https://doi.org/10.15760/honors.1108

This Thesis is brought to you for free and open access. It has been accepted for inclusion in University Honors Theses by an authorized administrator of PDXScholar. Please contact us if we can make this document more accessible: pdxscholar@pdx.edu. 
Should synergy alone be accepted as justification for premia paid in M\&A?

By

\title{
Sebastian Araguas
}

An undergraduate honors thesis submitted in partial fulfillment of the

\author{
requirements for the degree of \\ Bachelor of Arts \\ in \\ University Honors \\ and \\ Business Administration: Finance
}

Thesis Adviser

David Shankar

Portland State University 


\begin{abstract}
Synergy is often used by management as justification to pay, and oftentimes overpay, for acquisitions. This paper explores the phenomenon of synergy being used as justification for overpayment in various M\&A transactions, and the impact it has on value for shareholders. Current methods of valuation are compiled, summarized, and examined for potential areas of conflict, challenges with post merger integration are explored, and real world examples of improper integration and overpayment are examined. We find that the current methods of valuation leave room for error based on hubris and personal interest, that the realization of synergy is often much more challenging than forecasted, and that lack of synergy realization can come at a hefty price to company shareholders.
\end{abstract}

\title{
Introduction
}

For larger companies seeking external growth as organic growth declines, or for smaller companies seeking to increase their overall rate of growth, mergers and acquisitions (M\&A for short) are an attractive option. Despite their overall transactional and integrational difficulty, the market for mergers and acquisitions has grown significantly in recent years. Since 2013 there has been an estimated $\$ 10$ trillion USD in domestic transactions (Thompson et al., 2020). Other attractive reasons for managers in regards to mergers and acquisitions are the potential for synergies with an acquired company. In theory, the acquisition of other companies allow for all sorts of synergies ranging from improvements in operational efficiency, to lower capital costs thanks to greater size and diversification (Slusky \& Caves 1991). Unfortunately, due to the competitive landscape of the M\&A market nowadays it has become increasingly difficult to successfully complete an acquisition at a cost that would be on par with a company's valuation, 
and thus to extract the same amount of value that was achievable in previous years. In order to justify the increasingly large premiums being paid for target companies, management often uses the idea of potential synergies that can arise from the transaction. The danger of such a notion is that if the deal goes awry, the cost to shareholders can be catastrophic. The paper seeks to perform a critical review of the existing literature to analyze the prevailing valuation methods for transactional synergies, the difficulties in integrating a company post merger, and ultimately the repercussions of failing to properly value or integrate a company properly. To do this, an analysis of the different methods of valuation currently in practice will be conducted, followed by an analysis of the factors that lead to challenges in synergy integration, and lastly an examination of real world examples of failure to value or integrate a company properly. Through the critical review of literature we find shareholders and senior management should not accept synergies alone as justification to pay a premium for a company as they are difficult to value, difficult to realize, and both overpayment and unrealized synergies can result in the destruction of shareholder wealth.

\section{Background Information}

Before delving into the factors impacting the pricing justification used by these companies, it's important to gain an understanding of the common industry terminology, the driving factors behind M\&A deals, and the common justifications behind them. Starting with the terms "mergers" and "acquisitions", the term "merger" can be defined as " a consolidation of two or more independent companies whereby at least one part loses its autonomy" (Schade, 2013 , p.4). Whereas an acquisition can be defined as "a purchase of a company, part of a company, majority- or minority ownership (Schade, 2013, p.4). With that said, many authors and 
industry professionals tend to use the terms interchangeably, and the specificities of the terms will vary paper by paper (i.e. some papers might only call it an acquisition if it was hostile). For the purposes of this paper the transactions explored will simply be referred to as "M\&A deals" to encompass various types of transactions, and to avoid confusion. This allows for greater comparability overall and will prevent the subjectivity or exclusion of different deals based on criteria that isn't used industry wide. Schade (2013) offers further categorization for M\&A deals, being conglomerate, horizontal, and vertical (p.4). A conglomerate M\&A deal is one that takes place between entities that do not operate within the same industry. A vertical M\&A deal is one in which companies operate in the same industry, but "operate on different steps of the value chain" (Schade, 2013, p.5). Lastly, a vertical M\&A deal is one in which the two companies operate within the same industry and along the same value added step. This paper will examine all types of the aforementioned M\&A deals, but the frameworks discussed for valuation will be categorically agnostic. The goal of this paper is to draw conclusions that can be applied generally across industry, size, and scope making it applicable to as many different deal types as possible. Further terms of note include synergy, economies of scale, and economies of scope. Beginning with synergy, Schade (2013) offers the definition as "synchronic interactions of previously independent companies, subsidiaries or functional departments, which lead to an increase of the company value" (p. 13). As for economies of scale and scope, the former is in reference to the idea that a larger production leads to lower production costs, and the latter refers to the idea that the average production costs of several goods is reduced through scale.

In theory, a merger or acquisition should always be motivated by the same principle that drives a businesses other decisions, the desire to create value for shareholders. However, in practice, we see that this is not always the case. According to Berkovitch and Narayanan (1993), 
the three overarching motives for a company to merge with/acquire another company are as follows: synergy, agency, and hubris. Beginning with synergy, a bidding company would target a company that they believe would allow for certain efficiencies to be achieved that the separate entities wouldn't be able to capture when operating independently. Synergies that management look for across all industries tend to fall into three different buckets: operational, financial, and revenue. The two most common of which include financial and operational synergies. Operational synergies arise when two companies are able to increase their operational efficiency or reduce their operational costs in a way that they wouldn't be able to do as separate entities. Examples of operational synergy include the use of operating assets (i.e. factories) more efficiently, and the ability to consolidate operational expenses (i.e. staff reduction), with Devos et al. finding that cost reduction accounting for larger gains between the two (2009). Both economies of scale and economies of scope would be examples of operational synergies as well. Moving on to financial synergies, there are several types of financial synergies for management to seek out. Firstly, management of a financially healthy company could identify a company that is restricted by their capital situation, either due to credit or liquidity challenges, and acquire said company. Management would then in theory be able to alleviate such challenges, and the new value that is unlocked through the removal of such challenges would be considered the synergy. Another synergy management would look for is the ability to reduce their overall cost of capital by merging with another financially healthy company. The merged entity would be larger and in theory less of a financial risk, allowing them to raise capital at a lower rate and pursue more projects than they otherwise would have been able to operate independently. Lastly, there are a number of tax benefits that can arise from M\&A which oftentimes contribute largely in the aforementioned diversification motivated mergers (Devos et al., 2009) . Lastly, there are revenue 
synergies. Revenue synergies are the most difficult to quantify and realize, so they are often not weighted as heavily by the acquiring entities management. Revenue synergies arise when companies are able to generate additional revenue post integration, through the use of methods such as cross selling (if the companies customers are complementary) or intellectual property. Shifting gears into the agency motive for M\&A, it can be defined as deals motivated by the enhancement of the acquiring management's welfare, at the expense of the acquirer's shareholders (Berkovitch and Narayanan, 1993). Exploring the agency motive further we can see that motivating factors for the managers in this instance can include diversification of their personal portfolio, use of free cash flow to increase the size of the firm, and acquiring assets that would further increase the firms dependence on the aforementioned management. Seth et al. find that in a study of cross border M\&A deals, managerialism (agency motive) was the driver behind the observed value-destructive mergers in their study (2000). Regardless of the specific motive behind an agency motivated merger or acquisition, it almost certainly costs both the acquiring and acquired company's shareholders a great deal, and should be avoided at all costs (Berkovitch and Narayanan, 1993). Lastly, the hubris hypothesis purports that certain acquisitions are motivated by managers' mistakes, and that the anticipated synergies they sought to capture aren't there. It's quite common throughout the industry for managers who are plenty competent become too attached to a deal, and thus ignore the signs pointing to the problems with the transaction (Eccles et al., 1999). Hubris as a motive for acquisition can be detrimental to the acquiring company's shareholders, in the form of a transfer of wealth from the bidding company to the target company. This transfer of wealth occurs due to the premium paid in the acquisition by the bidding company, which due to the lack of transactional synergies to capture, represents a direct transfer to the target company (Roll, 1986). The hubris hypothesis tends to be the most difficult 
of the three to identify, as M\&A deals are rarely solely motivated by hubris, and thus it can play a role in value creating mergers as well (Seth et al., 2000).

\section{Section 1 - Synergy Valuation: An exploration of methodology and room for error Section 1.1 - Methods of Valuation Explored}

This section will seek to explore the discourse surrounding the current methods of valuation being used throughout the M\&A process. The established methods and frameworks will be examined in the context of the benefits and drawbacks of them in practice, and more specifically in the context of their pertinence in relation to the thesis. Both established and prevailing valuation methods will be explored throughout this section. The methods explored throughout this section have been compiled from the research of de Graaf \& Pienaar (2013), Patena (2011), and Pereiro (2018). After defining and exploring the methods, they will then be further evaluated in section 1.2 in regards to potential misuse.

de Graaf and Pienaar (2013) offer a compilation of prevailing methods used in the valuation of synergies throughout the M\&A process. The methods they propose can be divided into two categories: methods used for general synergy valuation, and methods used for the valuation of specific sets of synergies. Due to the scope of the paper, only the methods with application to multiple types of synergies will be examined. The aforementioned methods include the "outside-in approach", the standard discounted cash flow analysis, and the Monte Carlo simulation.

The "outside-in approach" was developed by Mckinsey and Co, and can be broken down into a four step process. The first step being the development of an industry specific business system; the second step being the development of baseline costs under the assumption that both 
entities had remained independent; the third step being the forecasting of expected cost synergies by category using the expertise of experienced line managers; lastly the fourth step involves comparing the improvements with "margin and capital efficiency benchmarks for the industry", and examining if the estimates are realistic given the data (de Graaf and Pienaar, 2013). This approach is essentially a more thorough derivation of the comparables valuation method for overall company valuation tailored to value synergies specifically, that incorporates a large amount of internal analysis as well. The strengths of this approach is that the inputs are derived from historical transactions which allows for a better picture of how a synergy would be valued in a successful transaction. Moreover, this practice challenges the rather commonplace (and simplistic) assumption that the target company's margins will by default increase to those of the acquirer. The ability to challenge such an assumption is invaluable when management is considering the true value of both operational and financial synergies. Unfortunately this approach suffers in practice due to the necessity of recent and relevant previous transactions. Numerous factors including industry and novelty of both the type of transaction and type of company being acquired can make it extraordinarily difficult to generate a sufficiently relevant set of comparable transactions. With that said, there is still a significant amount of input that can be derived from internal information alone, which allows it to overcome many challenges a traditional comps analysis wouldn't be able to, and makes it a strong candidate for synergy valuation. The second method of valuation covered by the authors and arguably the most established industry wide is the use of the discounted cash flow analysis. In essence, through the use of various assumptions the expected future cash flows of a given synergy are calculated and then discounted back to the date of the transaction. One of the strongest perks of using the DCF method of valuation is that it is one of the few prevailing methods that properly accounts for 
time. The importance of properly accounting for time in the calculation of synergy cannot be overstated, since as will be discussed later the integration time of synergies can significantly affect their likelihood of realization. Thus the DCF would allow for a sensitivity analysis to be conducted which would allow management to examine different scenarios of synergy realization. Although the most common, the DCF method of valuation can be the most problematic. The results of a DCF are heavily influenced by several factors that can be easily manipulated to serve a particular interest, such as the assigned growth or discount rate. In order to mitigate this potential issue, deGraaf refers to the work of Evans and Bishop (2001) who propose that all assumptions should be rigorously questioned by the involved parties and that estimates used should always be conservative. Unfortunately this framework relies on management to rigorously challenge their own inputs, and depending on the motive of the managers creating the analysis that simply might not be enough. The conservative approach and rigorous questioning proposed by the author could help to mitigate this issue, but in the accelerated timetable that most M\&A deals operate under, the ease of manipulation, and the subjectivity of the analysis can pose a significant challenge to properly question the analysis or the assumptions used throughout.

The last method of valuation the author explores, the Monte Carlo simulation, is one that works best in conjunction with other methods of valuation. The strength of the Monte Carlo simulation is in its ability to work through complicated problems with uncertain outcomes. The value of such a simulation would be the ability to gain insight into the likelihood of different outcomes that a potential merger or acquisition could produce. Although a method with promising potential in the world of synergy valuation (and business in general), this use of it in 
practice is quite rare. Thus de Graaf and Piennar consider it far more experimental than the previous two methodologies covered above.

In practice, the reality is that a company will likely use a combination of the above methods in order to create a range of values based on different assumptions, and as a result selecting the final value, or what will be decided as the proper valuation of the company, can prove to be challenging. That's where the Portfolio Approach to Equity Valuation comes in. The PATEV method of valuation was explored in Wiktor Patena's paper Company Valuation. How to deal with a range of values? This approach offers a significantly less subjective method at assigning an accurate final value to the target company. Patena establishes the method with the understanding that a company's value can be derived from using one (or a combination of) four different methods: the income-based methods, asset-based methods, comparative methods, and real options. To better understand the methodology, Patena offers an example in which both an asset and income based value have been generated for a specific company. In one situation, the income based valuation far exceeds the asset based valuation (in this case due to a company with strong financials deriving most of its cash flows from current assets). The other situation proposed is one in which the asset based valuation produces a far higher valuation than the income based valuation (this could be due to the possession of properties that have appreciated significantly or the aforementioned company operating in a heavily asset reliant industry). In both cases neither method of valuation is "correct" or "incorrect", the valuations simply need to be contextualized. This is the primary utility of a method such as PATEV. The use of PATEV assigns a weight to both values objectively, essentially assigning a greater weight to the larger valuation. In the cases that we just explored, the PATEV approach would essentially prevent the asset based valuation from disproportionately affecting the final value, and in the latter case 
would produce a valuation suggestive of either liquidating the business and ceasing operations or liquidating non-essential assets and relocating. The ability to normalize such disparate valuations between the two methods is one of PATEV's greatest strengths. However, there is a large weakness worth mentioning in this approach. Chiefly, the analyst conducting the valuation must validate the larger value, essentially verifying that the higher value generated is actually representative of the produced valuation. Unfortunately this is where subjectivity is able to make its way into a relatively objective approach, and allows for the manipulation of the data.

The last approach to explore in relation to the valuation of synergies is the incremental economic value added method proposed by Luis Pereiro. The focus of this methodology surrounds operational synergies, and more specifically the ability for a bidding company to improve the performance of a target company. Pereiro's (2018) argument is that in essence, existing methods of valuation do not properly take into account the difficulty in closing the performance gap between both bidder and target company and the methodology that the bidding company will use to close said gap. Thus, the function of the IEVA method is to estimate the actual gap in financial performance between the two companies and at the value extraction strategy that will likely be employed by the acquirer (Pereiro, 2018). The IEVA method operates under two assumptions, the first being that the ceiling of these synergies is the operational efficiency of the bidding company, and that the strategy employed by the bidder will likely be the strategy it is most proficient in using.

With those assumptions established, the actual method of calculation can be examined. The metric used by Pereiro to evaluate the success of these synergies is the return on capital employed, or ROCE. ROCE is calculated as a company's operating profit after taxes divided by its capital employed. Thus to arrive at economic value added, we would take the ROCE and 
subtract the weighted average cost of capital and multiply the result by capital employed. That brings us to the final portion of the calculation, in which we calculate the incremental economic value added. The IEVA can be calculated as the post acquisition ROCE less the pre acquisition ROCE which would then be multiplied by the capital employed, and then discounted to the present by dividing our IEVA over the target's WACC. Pereiro's method is the most objective in both input and output of the methods that we have discussed throughout the paper thus far. However, this approach is relegated almost exclusively to the calculation of operational synergies, and thus still leaves much room for error in the overall valuation process.

All of the methods explored in this section thus far have their merit for use in the valuation of synergies, but all of them leave room for error from hubris or manipulation of the managers that employ them throughout the acquisition process.

$\underline{\text { Section } 1.2 \text { - Hubris, Agency, and Room for Error in Existing valuation methods }}$

With an understanding of the different methods of synergy valuation used in practice today, it's possible to examine how each of them might be manipulated or misused. The importance of such understanding is paramount as claims of synergy as justification to pay exorbitant premiums for a target companies is seldomly are these claims generally accepted or used by management without much thorough examination (Kode et al., 2003). De Graaf puts it best in that "the danger with vague notions of M\&A Synergy is that they can and frequently do disguise other transaction motives" (de Graaf \& Pienaar, 2013). The motives referenced by de Graaf can essentially be assigned to two different general categories, agency and hubris.

Beginning with hubris, the hubris hypothesis as defined in the introduction purports that managers make mistakes when evaluating target firms and engage in acquisitions where there is no synergy. Through an analysis of 330 tender offers (Berkovitch and Narayanan, 1993) establish 
a framework for identifying the prevailing both agency and hubris in M\&A, while also being able to identify deals with value creating motives. To do this, they assign motive based on the results of different transactions in three aspects, gain (loss) to the target, gain (loss) to the bidder, and overall gain (loss) of the transaction. They infer that for value creation (in this case synergy) to be the motive in a transaction, all three categories must have measurable gain and a positive correlation with each other. The theory behind that hypothesis being that there were tangible synergies to be realized in the transaction. Whereas for the motivation to be agency, there has to be an inverse relationship between total and target gains, and between acquirer and target gains. The negative relationship here demonstrates a transfer of wealth from the bidding firm to the target firm, to the degree that the target firm has bargaining power and the ability to extract value in the transaction. Because of this, the overall gains in the transaction would be low (if existent) which would lead to the inverse relationship between target and overall gains (that would also hold between target and acquirer) Lastly, in the case of hubris, there would be a negative correlation between target and acquirer gains with no correlation between target and total gains. Since the hubris hypothesis essentially states that the acquiring managers made a mistake in overvaluing the synergies, it stands that the premium paid in the deal would essentially be a transfer of wealth between the bidding and target firm. However, there would be no correlation in overall gain since the total transactional gain would be zero (there is no value being created). The findings of the study were that nearly a quarter of all M\&A transactions were motivated by agency, and that from the subsample of negative total gains the mean total loss was \$146.5 million (Berkovitch and Narayanan, 1993). The results also found that in the other three quarters of transactions primarily motivated by synergy, the presence of hubris was also likely. That said, the authors conclude that the largest source of value-reducing transactions was due to 
agency, not hubris. Seth et al. found the same trend in their analysis of cross-border M\&A transactions several years later (2000). Although hubris played a role in many of the value generating transactions they studied, it was managerialism that caused the main source of value destruction, not hubris.

What factors then could allow for nearly a quarter of all transactions leading to the destruction of shareholder wealth? To understand this better, it's important to revisit the valuation methods and their weaknesses mentioned above. All of the methods have aspects that can be exploited by management with self-serving motives. For the "outside in approach", the cherry picking of comparable transactions and the use of managers that would provide the desired valuation leave the door open for the agency motive. The DCF method of valuation has several inputs that can be easily manipulated by management to display the numbers they need to justify an acquisition. PATEV can be manipulated by averaging values that would corroborate the perspective of senior management, and lastly the inputs in Perriero's methodology can be influenced in a similar manner to those of the DCF.

\section{Section 2 - Difficulties in Synergy Realization and Impact on shareholders}

Challenges in post-merger integration of synergies

As established in the last section, synergy valuation is far more of an art than it is a science, and without proper postmerger integration the valuations calculated are nothing more than visions of potential success. In the words of Kamal and Sangita Ray (2013), "Post-acquisition integration is the key to professionally unlocking the growth opportunities". Further adding to the complicated nature is the room for motives other than those beneficial to shareholders to appear throughout the deal making process. Thus, regardless of the motive of the 
initial deal, it falls on the managers of the post-merger integration process to realize the value promised throughout the valuation stage of the process. Management must do this despite complicating factors such as inaccurate valuation of the target company and the numerous tangible and intangible factors that need to be dealt with throughout the post-merger integration process. The challenges and best practices of such integration will be examined throughout this section. Factors that will be considered include time management, cultural differences, and improper implementation of post-merger plans.

The first difficulty managers will encounter in post-merger integration is the proper management of time. The first timeline that managers will have to successfully navigate is the time between deal close and the beginning of integration. According to Colombo et all, that time in particular has the potential to have the most negative effect on the performance of the acquisition. Moreover, challenges in the actual integration phase are sensitive to the assumptions made during the deal making process. Unfortunately it is often the case that ease of integration is far overestimated and the time to realize synergies is often underestimated (Goold \& Campbell, 1998). Managers are left with a difficult situation to manage as making too many sacrifices for short term gains threaten the ability to realize long term gains, but if managers wait too long it becomes increasingly difficult to realize any synergy at all (Eccles et al., 1999; de Graaf and Pienaar, 2013). This in combination with overly aggressive valuations of potential synergies put management in an optimism trap that can easily lead to the failure of any given M\&A deal.

One of the most tricky factors management will have to overcome is the proper integration of human capital. The integration of which is incredibly important as it plays a large role in the success of operational synergy. Adding to this difficulty is the impact employee morale can have on post-merger integration is hard to value, easy to underestimate, and difficult 
to manage throughout the integration process. A 1995 case study found that the idea of "culture shock", or the clash of two corporate cultures, lowered both employee satisfaction and commitment (Buono et all, 1995; Rotting et al, 2013). Another study of 30 acquisitions in the United States found that the mere perception of cultural difference had a negative impact on the creation of value for shareholders (Chatterjee et al., 1992; Rotting et al, 2013). Lastly, a study of 173 acquisitions in the United States found that differences in management styles are negatively related to post merger performance (Datta, 1991; Rotting et al, 2013). Other intangibles that can impact employee morale include overall outlook on M\&A deals and their tendency to lead to layoffs. The importance of proper management of these factors pertaining to human capital cannot be overstated in regards to operational synergy realization. However, active management and proactive vigilance of these issues throughout the process can reduce culture clash and help mitigate potential problems going forward.

The above issues are only exacerbated in the case of cross border mergers and acquisitions, or CBMA's for short. Building on the issues of managing inter-organizational cultural differences, CBMA's must also deal with cultural differences at the national level. Cultural distance includes factors such as language barriers, social structure, cultural norms, politics, etc. The research on how this impacts the success of transactional integration is far from settled, but the general consensus seems to be that there is potential for it to either add or detract from the new entity depending on how it is managed (Krug and Nigh, 2001; Very and Schweiger 2001; Rotting et al, 2013). Proper management of this aspect of human capital can yield a more diverse entity that is able to communicate better and more effectively across many mediums. However improper management can yield the potential for language barriers to obstruct communication of key information related to transactional success, and the propensity of these 
transactions to evoke an emotional (and sometimes nationalistic) reaction from the target company's employees. In one study cultural differences were cited as the principal factor behind the failure of the mergers that were studied. Lastly, studies also cite that overall success is strongly associated with employee's perception of compatibility between their current culture and the one of the bidding company. Moving on to non culture related difficulties, CBMA's have to consider operational differences in other countries. In a survey conducted by Basmah and Rahatullah (2014), Savola's acquisition of a Jordanian real estate company is a perfect example of the difficulties offered by international operating differences. This particular acquisition was one that would fall into the bucket of conglomerate deals as real estate was a different industry than Savola's altogether. Properly integrating a company that differs from your own operationally is difficult enough, but adding the unfamiliarity of a new country adds a new level of difficulty that in this case made it too much to handle. The combination of an unfamiliar industry and management's lack of experience operating in Jordan made it nearly impossible for the proper integration of the acquired company. This ultimately led to the failure to realize any of the anticipated value of this transaction. A subsequent example provided by Savola in Basmah and Rahatullah's (2014) survey was their acquisition of an edible oil company in Kazakhstan. The largest impacting factor in this acquisitional failure was the inability to properly integrate the value creation mechanisms of the two companies. Both of these instances exemplify how causal ambiguity can make post merger integration incredibly difficult.

Another potential for conflict in the post-merger integration process is the management amnesia phenomenon. This "amnesia" is defined essentially as management forgetting the anticipated difficulties and necessary steps to realize the synergies they forecasted in the initial valuation. In essence this principle describes how a promising acquisition with real opportunity 
for synergy can go awry. In the words of Jerry Levin, "Vision without execution is hallucination" (Feloni, 2018). The opportunities identified during the process of due diligence and valuation can quickly disappear when management doesn't proceed with the integration process as planned. A great example of this provided by Fiorentino and Garzella (2015) is the failure of KLM to integrate Alitalia. Alitalia was an Italian airline with a strong domestic presence but had serious capital limitations and was unable to offer long haul flights. KLM on the other hand had no presence in Italy, and was much healthier in terms of their financial position. The complementary aspects of both companies could have produced a significant synergy despite the very real difficulties they identified would arise during integration (caused largely by cultural and leadership disparity). Ultimately, the merger process was terminated due to management's situational "amnesia" and thus their inability to overcome the challenges that they had identified.

\subsection{The impact of unrealized synergies on shareholders}

Unrealized synergies often lead to the destruction of shareholder wealth for the acquiring company and in particularly problematic situations for the target company as well. The consequences of a loss of just one percent in return on investment can be a loss of shareholder wealth to the tune of hundreds of millions of dollars (Chanmugam et al., 2005). Ismail (2011) found that in their long term study of value generation post transaction that when the bidding firm overpaid for the target firm it led to a loss of wealth for the acquiring company's shareholders. This section will closely examine a handful of M\&A deals that failed to generate any sort of shareholder wealth either due to the overpayment for an acquisition, the lack of synergy realization, or both. The selected transactions to be examined will be America Online and Time Warner, Daimler and Chrysler, and Ebay and Skype. Each transaction had its own 
unique set of challenges that lead to the failure in integration post merger, and those factors will be explored in the context of the factors discussed above.

First and foremost is the America Online and Time warner merger. Americal Online (more commonly known as AOL) and Time Warner made the decision to merge in the year 2001 on the basis of conquering the newest media form, the internet, with the expectation that other forms of media would soon be obsolete. The deal was worth an estimated $\$ 350$ billion USD, and despite AOL having less than half the cash flow of Time Warner, its stock was valued at twice the price. Due to the hasty nature of the deal, many senior managers didn't find out until the public did, and many had strong concerns about the deal. This ultimately led to cultural clashes between the companies as the executives at both companies were kept essentially in the dark. Despite concerns from top executives and the accelerated nature of the deal, the two companies proceeded with the merger, and just a year later the company had to write down $\$ 99$ billion dollars. Moreover, the stock of the combined entity was trading at a $90 \%$ discount to peak value (Malone, 2010). In reality the merger was doomed from the start due to its astronomical valuation, and there was little that management from either company could do to make up for that fact. Ultimately the failure to accurately value the merger and the accelerated timeline lead to the death of a merger that in reality could've had potential at the right price.

The next deal to be examined will be Daimler's acquisition of Chrysler in 1998. It became quickly apparent that the cultural differences between the two companies would complicate the merger in many unforeseen ways. The merger had to deal with differences in culture at both the company and national level, which as discussed above can be especially problematic. These differences proved so polarizing that some felt the acquisition was doomed to fail before it was even completed. Dave Healey being one such person was quoted as saying 
"You had two companies from different countries with different languages and different styles come together yet there were no synergies." (Mateja, 2018). Despite opinions at the time even the CEO of Daimler admitted that they had strongly overestimated the potential for synergies (chicago tribune source). This in combination with the hostility Mercedes-Benz displayed towards Chrysler, and Chrysler's inability to compete with other foreign car makers in the United States domestic car market ultimately led to Daimler selling Chrysler at a nearly $\$ 30$ billion dollar loss. Hubris and overestimation of synergy (and thus overpayment) quickly led to the failure of this merger, and footed shareholders with a loss of nearly eighty percent.

Lastly, we'll examine another high profile acquisition, Ebay's acquisition of Skype. The main driver behind this acquisition was the anticipated synergies that Ebay saw from the integration of Skype. Ebay saw the acquisition as a way to generate serious revenue synergies through new methods of reaching customers, the ability to help customers make complicated or intricate decisions, and would allow Ebay to advertise on Skype's website (Mangalindan \& Rhoads, 2005). In reality, the synergies that Ebay thought could be realized through the Skype acquisition weren't there in practice, and they had a \$1.4 billion USD writedown (Ebay, Inc, 2014).

All of the above examples exemplify the consequences present to shareholders from M\&A deals gone awry. In all three of these cases, the use of synergy as justification proved to be incredibly detrimental and lead to significant write-downs, divestitures, or both. In the case of the Daimler Chrysler acquisition and the AOL Time Warner merger cultural differences inc combination with overvaluation lead to the destruction of shareholder wealth. All three examples are demonstrative of what can happen when valuation and post merger integration aren't given 
the scrutiny that they deserve, and in all three cases further due diligence could have saved management and shareholders plenty of headache and plenty of heartache.

\section{Conclusion}

The findings of this paper demonstrate that using synergy as a justification for premiums in M\&A deals risks the financial position of all parties involved. The current methods of valuation leave too much room for error and the precedence of ulterior motives means that the reliability of any given synergy valuation is seriously questionable. Moreover, the various challenges faced by both company's management in the post-merger integration process can lead to the death of what would otherwise be tangible and realizable synergy. Lastly, through the examination of three high profile M\&A failures it's apparent that the risk to shareholders is all too great if the deal fails to deliver on its promises. Ultimately more research should be conducted in the space and more techniques akin to the PATEV and ROCE should be developed to help combat both agency and hubris in the industry. All of this is not to say that synergies shouldn't be a factor in an M\&A deal, as plenty of successful deals with realized synergies have been performed in the past. However the claimed value of synergies should be thoroughly examined and questioned by all parties involved before a deal is completed. Doing so not only protects shareholders, but also the financial health of all parties involved in the deal. 


\section{Works Cited}

Basmah, A. Q., \& Rahatullah, M. K. (2014). Financial synergy in mergers and acquisitions. Evidence from Saudi Arabia. Aestimatio, (9), 182-198. http://stats.lib.pdx.edu/proxy.php?url=http://search.proquest.com.proxy.lib.pdx.edu/schol arly-journals/financial-synergy-mergers-acquisitions-evidence/docview/1638898681/se-2 ?accountid $=13265$

Berkovitch, E and Narayanan, M.P. (1993). Motives for Takeovers: An Empirical Investigation, Journal of Financial and Quantitative Analysis, 28(3), pp. 347-363. http://dx.doi.org/10.2307/2331418 1

Buone, A. F., Bowditch, J. L., \& Lewis, J. (1985). When cultures collide: The anatomy of a merger. Human Relations, 38, 477-500

Chanmugam, R., Shill, W., Mann, D., Ficery, K., \& Pursche, B. (2005). The intelligent clean room: Ensuring value capture in mergers and acquisition. Journal of Business Strategy, $26(3), 43-49$.

Chatterjee, S., Lubatkin, M. H., Schweiger, D.M., \& Weber, Y. (1992). Cultural differences and shareholder value in related mergers: Linking equity and human capital. Strategic Management Journal, 13, 319-334.

Datta, D.K. (1991). Organizational fit and acquisition performance: Effects of post-acquisition integration. Strategic Management Journal, 12, 281-297

de Graaf, A, \& Pienaar, A J. (2013). Synergies in mergers and acquisitions: A critical review and synthesis of the leading valuation practices. SA Journal of Accounting Research, 27(1), 143-180. https://doi.org/10.1080/10291954.2013.11435174

Devos, E., P. Kadapakkam , and S. Krishnamurthy, 2009, "How Do Mergers Create Value? A Comparison of Taxes, Market Power, and Efficiency Improvements as Explanations for Synergies," Review of Financial Studies 22, 1179-1211

eBay Inc. Reiterates 'The Truth About Skype'. About eBay: Company Info, News, Careers, Investor Relations. (2014, March 3).

https://www.ebayinc.com/stories/news/ebay-inc-reiterates-truth-about-skype/.

Eccles, G.E., Lanes, K.L. and Wilson, T.C. (1999). Are you paying too much for that acquisition? Harvard Business Review, 77: 136-146.

Evans, F. C. and Bishop, D.M. (2001). Valuation for M\&A: building value in private companies. New York: Wiley. 
Feloni, R. (2018, October 13). Billionaire investor Steve Case says the failure of the $2000 \mathrm{AOL}$ Time Warner mega merger taught him a crucial lesson about execution. Business Insider. https://www.businessinsider.com/steve-case-lesson-aol-time-warner-merger-2018-10.

Fiorentino, Raffaele, \& Garzella, Stefano. (2015). Synergy management pitfalls in mergers and acquisitions. Management Decision, 53(7), 1469-1503. https://doi.org/10.1108/MD-12-2014-0692

Ghosh Ray, Kamal, \& Ghosh Ray, Sangita. (2014). Cross-Border Mergers and Acquisitions: Modelling Synergy for Value Creation. In Advances in Mergers and Acquisitions (Vol. 12, pp. 113-134). Emerald Group Publishing Limited. https://doi.org/10.1108/S1479-361X(2013)0000012008

Goold, M. and Campbell, A. (1998). Desperately seeking synergy, Harvard Business Review, September-October, pp. 131-143.

Ismail, A. (2011). Does the Management's Forecast of Merger Synergies Explain the Premium Paid, the Method of Payment, and Merger Motives? Financial Management, 40(4), 879-910. https://doi.org/10.1111/i.1755-053X.2011.01165.x

Kode, G., Ford, J. and Sutherland, M. (2003). A conceptual model for evaluation of synergies in mergers and acquisitions: a critical review of the literature, South African Journal of Business Management, 34(1): 27-38.

Krug, J. A., \& Nigh, D. (2001). Executive perceptions in foreign and domestic acquisitions: An analysis of foreign ownership and its effect on executive fate. Journal of World Business, $36(1), 85-105$.

Malone, D. \& Turner, James. (2010). The merger of AOL and Time Warner: A case study. 16. 151-156.

Mangalindan, M., \& Rhoads, C. (2005, September 13). EBay to Buy Skype for \$2.6 Billion. The Wall Street Journal. https://www.wsj.com/articles/SB112651960619337861.

Mateja, J. (2018, August 24). How Chrysler marriage failed. chicagotribune.com. https://www.chicagotribune.com/news/ct-xpm-2007-05-15-0705141000-story.html.

Patena, W. (2011). Company valuation. How to deal with a range of values? eFinanse, 7(3), 75+. https://ink.gale.com/apps/doc/A298057214/GPS?u=s1185784\&sid=GPS\&xid=f329e1cd

Pereiro, L. E. (2018). The Estimation of M\&A Synergies: A New Approach. Journal of Corporate Accounting \& Finance, 29(4), 54-62. https://doi.org/10.1002/jcaf.22364

Roll, R. (1986). The hubris hypothesis of corporate takeovers, The Journal of Business, 59(2): 197-216. 
Rottig, D., Reus, T. H., \& Tarba, S. Y. (2013). The Impact of Culture on Mergers and Acquisitions: A Third of a Century of Research. Advances in Mergers and Acquisitions, 135-172. https://doi.org/10.1108/s1479-361x(2013)0000012009

Schade, V. (2013). Successful Management of Mergers \& Acquisitions. In Successful Management of Mergers \& Acquisitions. Diplomica Verlag.

Seth, A., Song, K.P. and Pettit, R. (2000). Synergy, managerialism or hubris? An empirical examination of motives for foreign acquisitions of U.S. firms, Journal of International Business Studies, 31(3): 387-405.

Slusky, A.R. and R.E. Caves, 1991, "Synergy, Agency, and the Determinants of Premia Paid Mergers," Journal of Industrial Economics 39, 277-296

Thompson, R., Dettmar, S., and Garay, M. (2020). The State of the Deal M\&A Trends 2020 [presentation]. https://www2.deloitte.com/content/dam/Deloitte/us/Documents/mergers-acqisitions/us-m na-trends-2020-report.pdf

Very, P., \& Schweiger, D. M. (2001). The acquisition process as a learning process: Evidence from a study of critical problems and solutions in domestic and cross-border deals. Journal of World Business, 36(1), 11-31. 